\title{
Hepatocellular carcinoma: natural history, current management, and emerging tools
}

\author{
This article was published in the following Dove Press journal: \\ Biologics:Targets and Therapy \\ 17 July 2012 \\ Number of times this article has been viewed
}

\section{Christopher L Tinkle \\ Daphne Haas-Kogan}

Department of Radiation Oncology, University of California, San Francisco, CA, USA

Correspondence: Daphne Haas-Kogan Department of Radiation Oncology, University of California, San Francisco, I600 Divisadero Street, Suite HI03I, San Francisco, CA 94II5-1708, USA Phone + I 4153537187

Fax + I 4153539883

Email dhaaskogan@radonc.ucsf.edu
Abstract: Hepatocellular carcinoma (HCC) is the most common primary liver tumor and represents the third-leading cause of cancer-related death in the world. The incidence of HCC continues to increase worldwide, with a unique geographic, age, and sex distribution. The most important risk factor associated with $\mathrm{HCC}$ is liver cirrhosis, with the majority of cases caused by chronic infection with hepatitis $\mathrm{B}(\mathrm{HBV})$ and $\mathrm{C}(\mathrm{HCV})$ viruses and alcohol abuse, although nonalcoholic fatty liver disease is emerging as an increasingly important cause. Primary prevention in the form of HBV vaccination has led to a significant decrease in HBV-related HCC, and initiation of antiviral therapy appears to reduce the incidence of HCC in patients with chronic $\mathrm{HBV}$ or HCV infection. Additionally, the use of ultrasonography enables the early detection of small liver tumors and forms the backbone of recommended surveillance programs for patients at high risk for the development of HCC. Cross-sectional imaging studies, including computed tomography and magnetic resonance imaging, represent further noninvasive techniques that are increasingly employed to diagnose HCC in patients with cirrhosis. The mainstay of potentially curative therapy includes surgery - either resection or liver transplantation. However, most patients are ineligible for surgery, because of either advanced disease or underlying liver dysfunction, and are managed with locoregional and/or systemic therapies. Randomized controlled trials have demonstrated a survival benefit with both local therapies, either ablation or embolization, and systemic therapy in the form of the multikinase inhibitor sorafenib. Despite this, median survival remains poor and recurrence rates significant. Further advances in our understanding of the molecular pathogenesis of HCC hold promise in improving the diagnosis and treatment of this highly lethal cancer.

Keywords: hepatocellular carcinoma, viral hepatitis, liver transplantation, ablation, embolization, sorafenib

\section{Natural history}

Hepatocellular carcinoma (HCC) is the third most common cause of cancerrelated death worldwide and the leading cause of death in patients with cirrhosis. ${ }^{1,2}$ Symptoms attributable to HCC are usually absent. Rather, patients typically manifest symptoms related to underlying cirrhosis, a condition present in $80 \%-90 \%$ of patients with HCC. ${ }^{3}$ Consequently, the majority of patients are diagnosed with advanced disease, often precluding potentially curative therapies. This has resulted, in part, in a 5-year overall survival rate of $12 \%$ and a median survival following diagnosis ranging from 6 to 20 months. . $^{3,4}$

When symptomatic, HCC is often associated with nonspecific complaints, including right upper abdominal or epigastric pain, early satiety, weight loss, and malaise. 
The onset of ascites, encephalopathy, jaundice, or variceal bleeding in patients with previously compensated cirrhosis should raise clinical suspicion for HCC. ${ }^{5}$ Rarely, patients may present with acute onset of severe abdominal pain and distension, hypotension, and a sudden drop in hematocrit resulting from tumor rupture and intraperitoneal bleeding. Emergent embolization of the bleeding blood vessel and/or surgery may be required for this complication. ${ }^{6}$

HCC is associated with a number of paraneoplastic syndromes resulting in hypoglycemia, erythrocytosis, hypercholesterolemia, hypercalcemia, severe watery diarrhea, and cutaneous manifestations. ${ }^{7}$ Extrahepatic spread at presentation is relatively uncommon, ranging between $10 \%$ and $30 \%{ }^{8-10}$ The most common sites of metastasis include lung, adrenal gland, regional lymph node regions (including the portahepatic and celiac lymph node chains), and bone. ${ }^{11}$ Importantly, extrahepatic nodal involvement is often difficult to assess based on cross-sectional imaging, as perihepatic lymphadenopathy is frequently present in patients with cirrhosis. ${ }^{12}$

\section{Risk factors and epidemiology}

The vast majority of cases of HCC occur in the setting of liver cirrhosis, and thus the etiology of HCC mirrors that of chronic liver disease and cirrhosis. Broadly, risk factors for HCC include viral infections, environmental toxins, comorbid conditions, inherited errors of metabolism, and autoimmune disorders. ${ }^{13}$ The unique geographic, sex, and age distributions of HCC are largely a result of the specific patterns of these risk factors, with the majority of cases the sequelae of hepatitis $\mathrm{B}$ and $\mathrm{C}$ viral infection and alcoholic liver disease. ${ }^{14}$

Chronic HBV infection (ie, hepatitis B surface antigen seropositivity) is the leading cause of HCC in Asia and Africa, where the virus is endemic and vertical transmission common. ${ }^{1,3}$ While HBV-induced HCC typically develops in cirrhotic livers, select populations of hepatitis B carriers remain at risk for $\mathrm{HCC}$ even in the absence of liver cirrhosis (Table 1). ${ }^{15}$ While the incidence of HCC in hepatitis B carriers depends on several factors, results from a prospective controlled study have revealed the annual incidence of $\mathrm{HCC}$ in hepatitis B carriers to be $0.5 \%$ in those without known cirrhosis and $2.5 \%$ in those with cirrhosis. ${ }^{16}$

$\mathrm{HCV}$ infection represents a major risk factor for $\mathrm{HCC}$, accounting for around one-third of cases in the United States and is thought, at least in part, to be responsible for the increasing incidence of $\mathrm{HCC}$ in the US. ${ }^{17,18} \mathrm{HCV}$ infection confers the highest risk of $\mathrm{HCC}$ in patients with cirrhosis, with an annual incidence ranging between $2 \%$ and $8 \% .{ }^{15} \mathrm{~A}$ prospective
Table I At-risk groups for which surveillance for HCC is recommended

\begin{tabular}{ll}
\hline Patients at increased risk for HCC & \\
\hline Cirrhosis & Without cirrhosis \\
\hline - Hepatitis B & Hepatitis B carrier \\
- Hepatitis C & - Family history of HCC \\
- Alcoholic cirrhosis & - Africans $>20$ years \\
- Nonalcoholic steatosis & - Asian males $\geq 40$ years \\
- Genetic hemachromatosis & - Asian females $\geq 50$ years \\
- Primary biliary cirrhosis & \\
- $\alpha-I$ antitrypsin deficiency & \\
\hline
\end{tabular}

(c) John Wiley and Sons 2012. Adapted with permission from Bruix and Sherman. ${ }^{15}$ Abbreviation: $\mathrm{HCC}$, hepatocellular carcinoma.

population-based study has revealed a 20 -fold increased risk of HCC in those with $\mathrm{HCV}$ infection compared to those without infection. ${ }^{19}$ While the incidence of HBV-related HCC has decreased after the initiation of a universal vaccination program, the incidence of HCV-induced HCC, where an effective vaccine is currently unavailable, is expected to continue to increase over the next several decades. ${ }^{3,20}$

Excess alcohol consumption is a well-recognized risk factor for HCC, although the threshold dose and duration are less clear. Furthermore, viral hepatitis is a frequent comorbid condition in many patients suffering from alcoholism, and infection with either HBV or HCV further increases the risk of alcohol-induced HCC. ${ }^{21,22}$ Cigarette smoking has also been shown to be a risk factor for HCC, and a recent Europeanpopulation-based case-control study revealed that smoking contributed to nearly $50 \%$ of all $\mathrm{HCCs}^{23}$ However, given the high prevalence of smoking in this population and the frequent comorbid conditions of alcohol and viral hepatitis, smoking likely represents a cofactor in the development of $\mathrm{HCC}$, rather than an independent etiologic agent. ${ }^{24}$

Epidemiologic studies have suggested a close correlation with obesity and diabetes and an increased risk of development of HCC. ${ }^{25-27}$ Both of these conditions are also strongly associated with the development of nonalcoholic steatohepatitis (NASH), an increasingly recognized cause of cirrhosis. ${ }^{28}$ A recent observational study of patients with cirrhosis due to either NASH or HCV infection revealed annual incidence rates of $\mathrm{HCC}$ of $2.6 \%$ and $4 \%$, respectively, suggesting that HCC surveillance may be indicated in NASHinduced cirrhotic patients. ${ }^{29}$ The most commonly associated environmental factor associated with HCC development is aflatoxin, a product of the Aspergillus fungus. High rates of dietary aflatoxin exposure, which commonly contaminates peanuts, soybeans, and corn, are frequent in developing countries and are associated with HCC..$^{30,31}$ 
Several inherited metabolic disorders of the liver have been implicated in the development of HCC, including alpha-1 antitrypsin deficiency, certain porphyrias, Wilson's disease, and hereditary hemachromatosis, each typically in the setting of cirrhosis. ${ }^{32-34}$ Additionally, a number of automimmune disorders have been implicated in HCC pathogenesis, including autoimmune hepatitis, primary biliary cirrhosis, and primary sclerosing cholangitis. ${ }^{13,33}$ Among these disease entities, available data suggesting that the incidence rate of HCC in patients with cirrhosis resulting from both hereditary hemochromatosis and advanced primary biliary cirrhosis appear significant enough to justify active surveillance. ${ }^{35-38}$

\section{Surveillance}

Surveillance is generally recommended in patients considered high risk for the development of HCC (Table 1). ${ }^{3,37,38}$ Evidence for the ability of surveillance to impact overall survival comes from a large randomized controlled trial conducted in China comparing no surveillance to semiannual evaluation of serum $\alpha$-fetoprotein (AFP) and abdominal ultrasonography (US) in HBV-infected patients or those with chronic hepatitis. ${ }^{39}$ Despite the fact that less than $60 \%$ of the patients in the surveillance arm were screened appropriately, a $37 \%$ reduction in HCC-related mortality was found. Additionally, several nonrandomized trials and observational studies have reported a survival benefit in patients ultimately diagnosed with early stage disease, the target population in which early treatment interventions would most likely provide meaningful improvement in survival duration. ${ }^{40}$

Thus, serum AFP and US are the most commonly employed methods for screening for $\mathrm{HCC}$, and while controversial, ${ }^{41}$ they are frequently performed in combination. The use of US in the detection of HCC generally results in $>60 \%$ sensitivity and $>90 \%$ specificity. ${ }^{42}$ However, US is highly operator-dependent, and the detection of tumors within a nodular cirrhotic liver is compromised and the sensitivity inferior. ${ }^{43}$ The sensitivity of AFP, using the commonly employed $20 \mathrm{ng} / \mathrm{mL}$ cutoff point, ranges between $25 \%$ and $60 \%,{ }^{3}$ and is compromised by the fact that AFP is frequently not elevated in early stage disease. As a result, the sole use of AFP as a screening tool is not recommended. The time interval of surveillance is dependent on tumor doubling time, and based on estimates for $\mathrm{HCC}$, is between 6 and 12 months. ${ }^{15}$ However, shorter interval follow-up has been recommended for cirrhotic patients with documented small liver nodules. ${ }^{44}$

\section{Diagnosis}

The modalities employed in the diagnosis of HCC depend on both the size of the lesion and underlying liver function, and include cross-sectional imaging, biopsy, and serum AFP. The incidental finding of a liver nodule, the detection of a liver nodule during surveillance US, or a rising AFP in the absence of a liver nodule on US, is typically followed by cross-sectional imaging. HCC lesions possess a distinct blood supply from the surrounding normal liver parenchyma, relying primarily on arterial blood from the hepatic artery while the surrounding liver is supplied mainly via the portal vein. ${ }^{45}$ Based on this, the use of four-phase (unenhanced, arterial, venous, delayed venous) helical computed tomography (CT) and dynamic contrast-enhanced magnetic resonance imaging (MRI) have established a classic imaging profile of HCC lesions characterized by arterial enhancement followed by hypointensity, or "washout," in the delayed venous phase. $^{46,47}$

Lesions less than $1 \mathrm{~cm}$ are generally followed by serial imaging every 3-6 months to assess changes in growth or vasculature that are suggestive of malignancy. Stability over a period of 1-2 years suggests the lesion is unlikely to be HCC. ${ }^{15}$ In cirrhotic patients or those with chronic liver disease, lesions greater than $1 \mathrm{~cm}$ in size that display both arterial enhancement and venous washout on either $\mathrm{CT}$ or MRI are considered diagnostic, and biopsy is typically not necessary. ${ }^{37,38}$ If, however, either of these classic imaging findings is not observed, complementary imaging is recommended, where again both imaging findings would be considered diagnostic of HCC. Discordant imaging on subsequent evaluation is frequently followed by biopsy. It should be pointed out that characterization of these-sized lesions is often difficult, and some experts recommend confirmation of enhancement and washout with both CT and MRI., ${ }^{3,48}$

In patients without underlying liver dysfunction, biopsy is generally recommended for lesions larger than $1 \mathrm{~cm}$ to confirm the diagnosis of HCC. Biopsy, either via fineneedle aspiration or core biopsy, unfortunately has several limitations, including sampling error, the inherent difficulty in discerning between high-grade dysplastic nodules and $\mathrm{HCC}$, and the remote possibility of seeding tumor cells along the needle track. ${ }^{49-51}$ Thus, in patients with a nondiagnostic biopsy, repeat biopsy and/or imaging are recommended.

The role of AFP in the diagnosis of HCC is controversial. While elevated levels of AFP in combination with a known hepatic mass have been shown to have a high positive predictive value in retrospective studies, AFP can be elevated in other primary liver malignancies as well as metastasis 
and is within normal limits in a large proportion of patients with known HCC. ${ }^{37,52-54}$ As a result, both the National Comprehensive Cancer Network (NCCN) and the American Association for the Study of Liver Diseases (AASLD) no longer recommend its use in the diagnosis of HCC. Additionally, while other serum biomarkers, including desgamma-carboxyprothrombin and lectin-bound $\alpha$-fetoprotein, have been investigated in both surveillance and diagnosis of HCC, they are not currently recommended. ${ }^{55,56}$

\section{Introduction to the management of HCC}

\section{Surgical resection}

Surgical resection (ie, partial hepatectomy) is the optimal treatment for HCC. Preoperative assessment aims to address both resectability and operability. Resectability focuses on two issues: anatomical constraints of the primary tumor(s) and the probability of extrahepatic spread, and is typically ascertained via four-phase dynamic CT or MRI of the liver. ${ }^{46,57}$ Given the most common metastatic sites of HCC, a chest CT and bone scan are most commonly employed to evaluate distant spread.

Assessment of operability relies on a variety of factors, including a patient's performance status, presence of comorbidities, severity of underlying liver disease, and estimates of the volume and function of the future liver remnant. The severity of underlying liver disease is most commonly determined through a combination of clinical and laboratory evaluation within the context of a scoring system, namely the Child-Pugh classification and the Model for End-Stage Liver Disease. However, additional information required to ensure adequate patient selection includes evaluation of portal hypertension, including clinical signs and symptoms, findings on CT or MRI, and/or measurement of the hepatic vein pressure gradient. ${ }^{58,59}$ Estimates of predicted postoperative liver volume and function are obtained through CT-based volumetric imaging, and these estimates have been shown to predict hepatic dysfunction in patients undergoing major liver resections. ${ }^{60,61}$ Finally, determination of the future liver remnant volume and function may be used to help determine if portal vein embolization, a technique employed to initiate hypertrophy in the anticipated liver remnant, is of value to extend the possibility of resection in otherwise suitable candidates. ${ }^{62,63}$

While thorough preoperative evaluation of the above parameters represents the standard of care, there are no fixed rules regarding tumor size, tumor number, presence of major vascular invasion, or extent of underlying liver disease.
However, optimal patient and tumor characteristics include normal hepatic function or compensated (Child-Pugh A classification) cirrhosis, no evidence of portal hypertension, sufficient future liver remnant, and solitary, intrahepatic tumor without evidence of major vascular invasion. ${ }^{37,38,64}$ While perioperative mortality ranges widely in modern retrospective series $(1 \%-24 \%)$, with more rigorous patient selection partial hepatectomy mortality rates are generally less than 5\%. ${ }^{65-68}$ Overall 5-year survival rates following resection of early stage $\mathrm{HCC}$ are often greater than $50 \%$, and in highly selected patients with solitary lesions without vascular invasion, survival rates greater than $70 \%$ have been reported. ${ }^{59,66,69,70}$

Despite impressive survival rates, surgical resection is limited by high rates of local recurrence, often exceeding numbers achieved with 5-year survival outcomes. ${ }^{15,71}$ In the majority of cases, this is thought to be secondary to occult micrometastasis within the remaining liver parenchyma rather than inadequate surgical resection, and thus both neoadjuvant and adjuvant therapies have been explored. However, at least one controlled trial examining the role of neoadjuvant transarterial chemoembolization and a metaanalysis of three randomized trials of adjuvant systemic chemotherapy have demonstrated a worse outcome compared with resection alone. ${ }^{72,73}$ Yet given the recent success of systemic targeted therapy in advanced HCC (see below), the role of the multikinase inhibitor sorafenib in the postresection setting is being explored. ${ }^{74}$

\section{Orthotopic liver transplantation}

Orthotopic liver transplantation (OLT) represents an additional potentially curative therapy for early stage HCC. In a landmark paper, Mazzaferro et al reported an 85\% 5-year survival and less than $10 \%$ recurrence rate of a highly selected group of patients with unresectable HCC who underwent liver transplantation. ${ }^{75}$ The shared tumor characteristics: solitary lesion $<5 \mathrm{~cm}$ or $<$ three lesions $<3 \mathrm{~cm}$ each, became known as the Milan criteria and have since been adopted by the United Network for Organ Sharing as the requisite tumor characteristics for potential transplantation for the treatment of HCC. Additional United Network for Organ Sharing criteria include lack of radiographic evidence of macroscopic invasion or extrahepatic spread. ${ }^{76}$ Importantly, subsequent studies in which the Milan criteria were employed have demonstrated similar outcomes. ${ }^{77,78}$

An area of active debate focuses on the possibility of expanding the Milan criteria in order to provide OLT to patients with higher-stage disease. Several centers using 
expanded criteria have demonstrated 5-year survival rates within the range of those achieved using the Milan criteria. ${ }^{79-81}$ Chief among these is the University of California, San Francisco, which has expanded criteria to include solitary tumors $<6.5 \mathrm{~cm}$ and $<$ three tumors $<4.5 \mathrm{~cm}$ and cumulative tumor size $<8 \mathrm{~cm}$. While wide variation in survival exists in studies using these criteria, a recent study demonstrated a 5 -year survival rate of $75 \% .{ }^{82}$ Despite this, given the correlation between tumor size and number and risk of dissemination and the critical shortage of liver donors, Milan criteria are considered the standard of care at most transplant centers. ${ }^{83}$

Given the importance of maintaining sufficient functional liver capacity following surgical resection for $\mathrm{HCC}$, it is generally accepted that first-line treatment for early stage HCC in patients with moderate to severe cirrhosis (Child-Pugh classes B and C) is OLT. However, with recurrence rates generally $\sim 10 \%$ with OTL versus up to $\sim 70 \%$ with surgical resection, optimal treatment for patients with compensated cirrhosis (Child-Pugh class A) with early HCC who meet the Milan criteria is controversial. ${ }^{84,85}$ There are currently no randomized controlled trials comparing these two modalities in this patient population, and current NCCN guidelines indicate initial treatment with either is acceptable. ${ }^{38}$

\section{Ablation}

The use of ablation for the treatment of HCC runs the gamut from agent used - toxic chemical agents (ethanol, acetic acid) or selective temperature gradients (radiofrequency, cryotherapy) - to method used percutaneous, laproscopic, or open. The anticipated end result of each method is the same, that of selective tumor necrosis, commonly assessed by a lack of contrast uptake on dynamic CT or MR imaging following treatment and assessment of periprocedure serum AFP. ${ }^{86,87}$

The two most frequently used methods include percutaneous radiofrequency ablation (RFA) and percutaneous ethanol injection (PEI). Percutaneous ablation is a well-tolerated procedure, with major complications generally less than $10 \%$ for RFA and less than $3 \%$ for PEI, and morbidity rates less than $1 \%$ for RFA and extremely rare for PEI. ${ }^{88-90}$ With regards to the optimal type of ablation, multiple prospective randomized controlled trials have demonstrated superior local tumor control with RFA, and three meta-analyses have demonstrated superior overall survival..$^{91-96}$ That said, the efficacy of complete control rates between RFA and PEI appears to be fairly similar for tumors less than $2 \mathrm{~cm} .{ }^{91,92,97}$ While both of these methods have distinct advantages and disadvantages, it is important to note that they are limited by tumor size and location. ${ }^{98-100}$

There is wide variation in reported overall survival rates, yet long-term studies of both RFA and PEI have achieved 5 -year overall survival of over 50\% . $^{101,102}$ Like survival outcomes, local recurrence rates range widely among studies. Results from a recent randomized controlled trial demonstrate local recurrence rates with both RFA and PEI to be between $13 \%$ and $34 \%,{ }^{103}$ while estimated 4 -year recurrence rates of $70 \%$ and $85 \%$ with RFA and PEI, respectively, were obtained in a separate randomized controlled trial..$^{93}$ On the other hand, a recent cohort study found a less-than-3\% recurrence rate at 31 months in select patients with tumors less than $2 \mathrm{~cm}$ treated with RFA. ${ }^{104}$

Given the generally comparable survival and recurrence rates of ablation to surgical resection for early $\mathrm{HCC}$, three randomized controlled trials have compared ablation with surgical resection. Two studies failed to show a significant benefit to surgery, with similar 3-year overall and disease-free survival. ${ }^{105,106}$ However, a recent larger study of patients with HCC meeting the Milan criteria demonstrated superior 5-year overall survival (76\% vs 55\%) and recurrence-free survival (51\% vs 29\%), as well as significantly lower overall recurrence rates (42\% vs 63\%) for those who underwent surgical resection compared to RFA. ${ }^{23}$ Taken together, most physicians favor surgical resection for patients with early HCC who are deemed both resectable and operable, even with small tumors. For nonsurgical patients with tumors less than $2 \mathrm{~cm}$, either ablative technique can be used and case-specific characteristics often guide ultimate treatment decisions, while RFA is generally preferred for larger tumors.

\section{Transarterial embolization}

The principle of embolization relies on the same biologic feature of HCC exploited by hepatic imaging used for diagnosis: selective hepatic artery blood supply to tumors. ${ }^{45}$ In the case of embolization, selective tumor hypoxia and resultant necrosis is achieved via significant reduction in arterial blood flow through the use of image-guided catheterbased infusion of particles. ${ }^{107}$ Much like ablation, there is wide variation in the types of particles used, types of antitumor adjuvants employed, types of emulsifying agents used with adjuvant treatments, and number of treatment sessions given, all of which complicate the interpretation of the many studies examining its clinical utility.

Broadly speaking, embolization can be categorized as transarterial embolization (TAE) (ie, bland embolization), transarterial chemoembolization (TACE), and transarterial 
radioembolization (TARE). In the case of TACE, transarterial infusion of a chemotherapeutic agent (frequently doxorubicin or cisplatin) with or without an emulsifying agent (commonly Lipiodol, an oily substance with selective tumor retention) precedes infusion of embolic particles. ${ }^{108}$ Newer methods of TACE have employed drug-eluting beads as a way to concomitantly reduce blood flow and deliver sustained and controlled adjuvant therapy and reduce systemic side effects. ${ }^{109}$

Conversely, radionuclide conjugation of Lipiodol (iodine-131 Lipiodol) is generally done in the absence of specific embolization and is thought to exert sufficient antitumor effect through selective high-dose radiation. ${ }^{110}$ Additionally, while radionuclide-conjugated microspheres (commonly yttrium-90) do exhibit microvascular occlusive properties based on sizing of microspheres, embolization is less dramatic and resulting tumor necrosis is thought to be mediated predominantly via radiation rather than ischemia. ${ }^{107,111}$

Two landmark randomized controlled trials involving patients with unresectable $\mathrm{HCC}$ with preserved liver function have demonstrated a significant survival advantage with TACE compared to best supportive care. In the study by Llovet et al, 112 patients were randomized to either TAE, TACE, or best supportive care, and survival probabilities at 1 year and 2 years were $75 \%$ and $50 \%$ for TAE, $82 \%$ and $63 \%$ for TACE, and $63 \%$ and $27 \%$, respectively, for supportive care. The study was stopped early after interim analysis revealed statistically significant survival advantage for TACE versus supportive care $(P=0.009)$; unfortunately, the study was underpowered to detect a difference between TACE and TAE. ${ }^{112}$ In the study by Lo et al, 80 patients were randomized to TACE vs best supportive care, and actuarial survival was significantly better in the TACE arm than in the supportive-care arm (1 year, $57 \%$ vs $32 \% ; 2$ years, $31 \%$ vs $11 \%$; 3 years, $26 \%$ vs $3 \% ; P=0.002) .{ }^{113}$

Based in part on these results, TACE has become the most commonly employed embolization technique. Several recent studies have subsequently compared "conventional" TACE with TACE using drug-eluting beads (DEB-TACE). While a retrospective study has suggested a survival advantage with drug-eluting beads, ${ }^{114}$ a recent phase II prospective randomized trial revealed comparable effectiveness with the two modalities, albeit with significantly less systemic toxicity with DEB-TACE. ${ }^{115}$ Additionally, results from this randomized trial as well as an additional randomized trial that compared DEB-TACE to TAE revealed nonsignificantly higher rates of complete tumor response and disease control with DEB-TACE. ${ }^{115,116}$ There are currently no published randomized controlled trials comparing TACE (conventional or with drug-eluting beads) with TARE employing yttrium-90 microspheres. However, a recent comparative effective analysis of patients with unresectable HCC treated with either TACE or TARE with yttrium-90 revealed similar median survival outcomes (20.5 months vs 17.4 months, respectively, $P=0.232$ ), while radioembolization resulted in significantly longer time to progression and reduced toxicity. ${ }^{117}$

While morbidity with embolization is relatively low, (generally $<5 \%$ ), complications are common and include a transient postembolization syndrome consisting of abdominal pain, nausea, ileus, and fever. ${ }^{112,118,119}$ Overall survival rates vary widely, yet studies with TACE and TAE reported 2-year overall survival ranging from $20 \%$ to $60 \% .^{112,113,120}$ However, durable long-term survival is rare with embolization, as initial complete response rates are low and revascularization within the tumor bed frequently occurs. ${ }^{15}$ Thus, it is generally not employed with curative intent.

\section{Systemic therapy}

Despite the fact that most patients with HCC present with advanced disease, prior to 2008 no systemic therapy had demonstrated sustained improved survival, including single-agent or combined cytotoxic chemotherapy, ${ }^{121,122}$ immunotherapy alone or in combination with cytotoxic chemotherapy, ${ }^{123,124}$ tamoxifen or antiandrogens, ${ }^{125-127}$ or somatostatin analogs. ${ }^{128,129}$ However, with the publication of two randomized placebo-controlled phase III trials, the oral multikinase inhibitor sorafenib has become the new reference standard for treatment of advanced HCC. ${ }^{130,131}$ Sorafenib inhibits both the rapidly accelerated fibrosarcoma (Raf) kinase and the vascular endothelial growth factor receptor (VEGFR) intracellular kinase pathways, resulting in suppression of tumor cell proliferation and angiogenesis. ${ }^{132,133}$

In the multicenter European Sorafenib Hepatocellular Carcinoma Assessment Randomized Protocol (SHARP) trial, 602 patients with advanced HCC who were systemic therapy-naive received either sorafenib or placebo until radiological or symptomatic progression. ${ }^{130}$ The study was stopped at the second planned interim analysis because of advantages in median overall survival (10.7 vs 7.9 months; hazard ratio, $0.69 ; 95 \% \mathrm{CI}, 0.55-0.87 ; P<0.001)$ and time to radiological progression (5.5 vs 2.8 months; $P<0.001$ ) in the sorafenib arm. However, objective response rates to sorafenib were low according to radiographic criteria, and sorafenib did not increase the time to symptomatic progression. The underlying etiologies of HCC were 
primarily HCV (28\%), alcohol (26\%), and HBV (18\%). The vast majority of patients had compensated liver disease and good performance status.

In the Asia-Pacific trial, the efficacy of sorafenib in the Asian population was evaluated in 226 patients in a similar design and dosing to the SHARP trial. ${ }^{131}$ Patients who received sorafenib again demonstrated significant benefits in median overall survival ( 6.5 vs 4.2 months; hazard ratio, $0.68 ; 95 \% \mathrm{CI}, 0.50-0.93 ; P=0.014)$ and time to radiological progression (2.8 vs 1.4 months) compared to placebo. While most patients again had preserved liver function, patients in the study tended to be younger, have more advanced-stage disease, and generally worse performance status. Additionally, the underlying etiology was different, with more than $70 \%$ of patients infected with HBV. These differences in patient and disease characteristics may account for the markedly reduced magnitude of benefit between the two trials (10.7 vs 6.5 months median overall survival). ${ }^{134}$ That said, the hazard ratio for survival was nearly identical between the two trials, suggesting comparable efficacy of sorafenib. Sorafenib was well tolerated with manageable side effects in both trials. Despite the fact that the original Food and Drug Administration approval of sorafenib in the US did not specify its use in underlying liver disease, current NCCN guidelines recommend sorafenib with Child-Pugh classes A and B only with unresectable, inoperable, or metastatic disease. ${ }^{38}$

\section{Emerging tools for early diagnosis and management}

Significant advances in diagnostic and therapeutic interventions are required to help transform $\mathrm{HCC}$ from a disease often diagnosed late and restricted largely to palliative therapies to one diagnosed early where curative intent is the goal. Core to this is the elucidation of the molecular pathways operative in HCC pathogenesis. Histopathologic analysis and epidemiologic studies of HCC arising in the setting of cirrhosis have suggested multistep hepatocarcinogenesis through the identification of morphologically distinct precancerous lesions, including dysplastic foci and dysplastic nodules, and early small $\mathrm{HCC}(<2 \mathrm{~cm}) \cdot{ }^{135,136}$ Yet the pathologic distinction between these types of lesions is often difficult and biopsies of small tumors carry a false-negative rate of $30 \%-50 \% .{ }^{137}$

Recent expression profiles of human samples have suggested particular mRNA expression subsets, or signatures, associated with both improved diagnostic accuracy and lesion discrimination. ${ }^{138-141}$ For example, a 13-gene signature identified through high-throughput quantitative real-time polymerase chain reaction in 128 patient samples provided high diagnostic accuracy for HCC. ${ }^{138}$ Additionally, the expression of three genes (glypican 3, lymphatic vessel endothelial hyaluronan receptor 1 and survivin), has been reported to provide $\sim 90 \%$ accuracy in distinguishing dysplastic nodules from early HCC. ${ }^{139}$ Results of many of these genomic studies have been applied to more conventional immunohistochemical analysis, and a recent prospective analysis of the protein expression of glypican 3, heat shock protein 70 , and glutamine synthetase revealed $72 \%$ sensitivity and $100 \%$ specificity in detecting well-differentiated HCC in biopsy samples. ${ }^{142}$ These markers have been validated in a larger number of patients and have recently been suggested as part of the diagnostic algorithm for the American Association for the Study of Liver Diseases. ${ }^{37,143}$

Serum levels of several of these biomarkers have also been evaluated in diagnosis and surveillance, including glypican 3, des-gamma-carboxyl prothrombin (DCP), and Lens culinaris agglutinin-reactive AFP, an isoform of AFP. ${ }^{144-147}$ While a recent study in a large population of patients with $\mathrm{HCV}$ associated HCC suggested an improved sensitivity with a combination of AFP and DCP compared with either alone, to date additional serum biomarkers beyond AFP have not been incorporated in major HCC management guidelines. ${ }^{55}$

Radiographic imaging also plays a key role in the early diagnosis of HCC, and is critical for accurate staging and treatment-response assessment. The major difficulty in diagnostic imaging of the cirrhotic patient remains the accurate characterization of lesions less than $2 \mathrm{~cm}$, and the incorporation of functional hepatic imaging and development of new contrast agents will likely improve the detection and characterization of these small tumors. Diffusion-weighted MRI has been shown to improve detection of HCC smaller than $2 \mathrm{~cm}$, with sensitivities higher than multiphasic MRI alone, and represents a promising technique given its ease of implementation into current clinical practice..$^{148,149}$

The use of two new hepatocyte-specific gadolinium chelate contrast agents, gadobenate dimeglumine (Multihance; Bracco, Milan, Italy) and gadoxetic acid (Primovist; Schering, Berlin, Germany), with multiphasic contrast-enhanced MRI has been shown to improve in the diagnosis of HCC over MRI or CT alone. ${ }^{150,151}$ These agents have also been shown to enhance the differentiation of small HCCs $(\leq 2 \mathrm{~cm})$ from arterial-enhancing pseudolesions, common benign hepatic vascular lesions that mimic early HCC..$^{152,153}$

[18F]fluorodeoxyglucose positron emission tomography (FDG-PET) is limited by the varying degrees of FDG 
Table 2 Select phase III trials evaluating sorafenib

\begin{tabular}{llllll}
\hline ID & Acronym & Active arm & Control arm & Primary outcome & Indications \\
\hline NCT0I009593 & BRISK-FL & Brivanib & Sorafenib & Overall survival & First line tx for advanced HCC \\
NCT0II35056 & SIRveNIB & Yttrium-90 microspheres & Sorafenib & Overall survival & First line tx for advanced HCC \\
NCT0090I90I & SEARCH & Sorafenib + erlotinib & Sorafenib & Overall survival & First line tx for advanced HCC \\
NCT0I0I5833 & - & Sorafenib + doxirubicin & Sorafenib & Overall survival & First line tx for advanced HCC \\
NCT0I004978 & - & TACE + sorafenib & TACE + placebo & Progression-free survival & First line tx for intermediate HCC \\
ISRCTN2408I794 & HeiLivCa & TACE + sorafenib & TACE + placebo & Time to progression & $\begin{array}{l}\text { Bridge therapy for liver } \\
\text { transplantation }\end{array}$ \\
NCT00494299 & - & Sorafenib & Placebo & Time to progression & $\begin{array}{l}\text { Prevention of recurrence } \\
\text { after embolization }\end{array}$ \\
NCT00692770 & STORM & Sorafenib & Placebo & Recurrence-free survival & $\begin{array}{l}\text { Prevention of recurrence } \\
\text { after resection or ablation }\end{array}$ \\
\hline
\end{tabular}

Adapted from Gastroenterology, I40:5, Villanueva A and Llovet JM, Targeted therapies for hepatocellular carcinoma, p. I7, @ 20II, with permission from Elsevier Ltd. ${ }^{163}$ Abbreviations: tx, treatment; HCC, hepatocellular carcinoma; TACE, transarterial chemoembolization.

accumulation in primary $\mathrm{HCC}$, and is not currently recommended in the diagnosis of HCC. ${ }^{37,38}$ While several studies have demonstrated a greater sensitivity for detection of distant metastasis with FDG-PET compared to CT, MRI, or radionuclide bone scan, its use is limited by high falsepositive rates and it is currently not recommended by the AASLD or NCCN. ${ }^{8,37,38,154,155}$ The use of new radiotracers, including $[11 \mathrm{C}]$ acetate may, however, improve the sensitivity and specificity of PET scanning in the diagnosis and evaluation of HCC. ${ }^{156}$

Assessment of tumor response to nonsurgical treatments has traditionally been based on changes in tumor size and number, delineated by the World Health Organization and the Response Evaluation Criteria in Solid Tumors criteria. ${ }^{157,158}$ However, these criteria are often inadequate for the evaluation of HCC, particularly as it relates to novel molecular therapies, which often result in tumor necrosis. ${ }^{159}$ Preliminary studies of both diffusion-weighted MRI and perfusion CT show promise in the evaluation of tumor response to both local ablative and systemic therapies. ${ }^{160-162}$

Elucidation of signal transduction pathways implicated in tumorigenesis and development of targeted molecular therapies have fueled a revolution in oncology, and this has impacted the management of HCC directly with the demonstration of a significant survival advantage with the use of sorafenib. Given this success, the role of sorafenib alone and in combination with traditional locoregional therapies, systemic chemotherapy and novel molecularly targeted therapies is currently being investigated in various stages of disease (Table 2). ${ }^{163}$ Additionally, alterations in several signal transduction pathways have been detected in HCC, including Wnt signaling, p53, insulin-like growth factor, Ras, epidermal growth factor receptor (EGFR),
Akt/target of rapamycin (TOR), c-MET, VEGFR, and fibroblast growth factor (FGF). ${ }^{164}$ This has resulted in the application of a myriad of new targeted therapies in both the preclinical and clinical setting, including the monoclonal antibodies bevacizumab (anti-VEGF) and cetuximab (antiEGFR), and the small molecule inhibitors erlotinib (EGFR inhibitor), brivanib (FGF and VEGFR inhibitor), everolimus (mammalian TOR inhibitor) and linifanib (VEGFR and PDGFR inhibitor). ${ }^{133}$

Many of these therapies target well-established proteins that regulate critical aspects of tumorigenesis, including angiogenesis, proliferation, and survival. However, recent work has implicated microRNA dysregulation in many of these processes during hepatocarcinogenesis, and early studies of human HCC microRNA expression profiling have suggested expression signatures predictive of metastasis and survival. ${ }^{165,166}$ Epigenetic alterations, including DNA methylation and histone modification, have also been implicated in the pathogenesis of HCC. ${ }^{164}$ Importantly, therapeutic interventions targeting some of these aberrant processes in the form of histone deacetylase inhibitors are currently being investigated in clinical trials of HCC. ${ }^{163}$

\section{Conclusion}

Hepatocellular carcinoma is an aggressive cancer that frequently occurs in the setting of chronic liver disease and cirrhosis. It is typically diagnosed late in the disease course, often precluding curative surgical therapies. Furthermore, concomitant liver dysfunction often further hampers both curative and palliative therapies. However, HCC is unique among many neoplasms in that effective preventative measures, including HBV vaccination, universal screening of blood products, use of safe injection practices, education and treatment of alcoholism and intravenous 
drug abuse, reduction in aflatoxin through control of fungal contamination, and initiation of antiviral therapy are in place and have been shown to be effective. ${ }^{13,167}$

Advances in locoregional therapies, including the use of drug-eluting beads and radionuclide-conjugated microspheres, represent strategies that may further improve survival among patients with intermediate-stage HCC and preserved liver function. Moreover, the demonstration of the safety and efficacy of sorafenib as a frontline treatment for advanced HCC in patients with preserved liver function represents a significant advancement in what was an otherwise bleak set of treatment options for this group of patients. Effective molecularly targeted therapies may also hold promise as adjuvants to primary surgical therapies, currently limited by high rates of disease recurrence. Finally, it is hoped that, much as has been shown for breast and colorectal carcinoma, active research aimed at the elucidation of the molecular pathogenesis of $\mathrm{HCC}$ and the identification of new biomarkers will result in further advances in the prevention, diagnosis, and treatment of HCC.

\section{Disclosure}

The authors disclose no conflict of interest.

\section{References}

1. Bosch FX, Ribes J, Cleries R, Diaz M. Epidemiology of hepatocellular carcinoma. Clin Liver Dis. 2005;9(2):191-211, v.

2. Jemal A, Bray F, Center MM, Ferlay J, Ward E, Forman D. Global cancer statistics. CA Cancer J Clin. 2011;61(2):69-90.

3. El-Serag HB. Hepatocellular carcinoma. N Engl J Med. 2011;365(12): 1118-1127.

4. A new prognostic system for hepatocellular carcinoma: a retrospective study of 435 patients: the Cancer of the Liver Italian Program (CLIP) investigators. Hepatology. 1998;28(3):751-755.

5. Bartlett DL, Di Bisceglie AM, Dawson LA. Cancer of the liver. In: DeVita VT, Lawrence TS, Rosenberg SA, editors. Cancer: Principles and Practice of Oncology, 8th ed. Philadelphia: Lippincott Williams and Wilkins; 2008:1129-1156.

6. Rossetto A, Adani GL, Risaliti A, et al. Combined approach for spontaneous rupture of hepatocellular carcinoma. World J Hepatol. 2010;2(1):49-51.

7. Kassianides C, Kew MC. The clinical manifestations and natural history of hepatocellular carcinoma. Gastroenterol Clin North Am. 1987;16(4):553-562.

8. Yoon KT, Kim JK, Kim do Y, et al. Role of $18 \mathrm{~F}$-fluorodeoxyglucose positron emission tomography in detecting extrahepatic metastasis in pretreatment staging of hepatocellular carcinoma. Oncology (Williston Park). 2007;72 Suppl 1:104-110.

9. Wudel LJ Jr, Delbeke D, Morris D, et al. The role of [18F]fluorodeoxyglucose positron emission tomography imaging in the evaluation of hepatocellular carcinoma. Am Surg. 2003;69(2):117-124; discussion 124-126.

10. Carriaga MT, Henson DE. Liver, gallbladder, extrahepatic bile ducts, and pancreas. Cancer. 1995;75(Suppl 1):171-190.

11. Katyal S, Oliver JH 3rd, Peterson MS, Ferris JV, Carr BS, Baron RL. Extrahepatic metastases of hepatocellular carcinoma. Radiology. 2000;216(3):698-703.
12. Dodd GD 3rd, Baron RL, Oliver JH 3rd, Federle MP, Baumgartel PB. Enlarged abdominal lymph nodes in end-stage cirrhosis: CThistopathologic correlation in 507 patients. Radiology. 1997;203(1): 127-130.

13. Sohal DP, Sun W. Hepatocellular carcinoma: prevention and therapy. Curr Oncol Rep. 2011;13(3):186-194.

14. McGlynn KA, London WT. The global epidemiology of hepatocellular carcinoma: present and future. Clin Liver Dis. 2011;15(2): 223-243, vii-x.

15. Bruix J, Sherman M. Management of hepatocellular carcinoma. Hepatology. 2005;42(5):1208-1236.

16. Beasley RP, Hwang LY, Lin CC, Chien CS. Hepatocellular carcinoma and hepatitis B virus. A prospective study of 22707 men in Taiwan. Lancet. 1981;2(8256):1129-1133.

17. Davila JA, Morgan RO, Shaib Y, McGlynn KA, El-Serag HB. Hepatitis C infection and the increasing incidence of hepatocellular carcinoma: a population-based study. Gastroenterology. 2004;127(5):1372-1380.

18. El-Serag HB, Mason AC. Risk factors for the rising rates of primary liver cancer in the United States. Arch Intern Med. 2000;160(21): 3227-3230.

19. Sun CA, Wu DM, Lin CC, et al. Incidence and cofactors of hepatitis C virus-related hepatocellular carcinoma: a prospective study of 12,008 men in Taiwan. Am J Epidemiol. 2003;157(8):674-682.

20. Zanetti AR, Van Damme P, Shouval D. The global impact of vaccination against hepatitis B: a historical overview. Vaccine. 2008;26(49): 6266-6273.

21. Befrits R, Hedman M, Blomquist L, et al. Chronic hepatitis C in alcoholic patients: prevalence, genotypes, and correlation to liver disease. Scand J Gastroenterol. 1995;30(11):1113-1118.

22. Donato F, Tagger A, Gelatti U, et al. Alcohol and hepatocellular carcinoma: the effect of lifetime intake and hepatitis virus infections in men and women. Am J Epidemiol. 2002;155(4):323-331.

23. Trichopoulos D, Bamia C, Lagiou P, et al. Hepatocellular carcinoma risk factors and disease burden in a European cohort: a nested case-control study. J Natl Cancer Inst. 2011;103(22):1686-1695.

24. Sherman M, Llovet JM. Smoking, hepatitis B virus infection, and development of hepatocellular carcinoma. J Natl Cancer Inst. 2011;103(22):1642-1643.

25. Wolk A, Gridley G, Svensson M, et al. A prospective study of obesity and cancer risk (Sweden). Cancer Causes Control. 2001;12(1):13-21.

26. Polesel J, Zucchetto A, Montella M, et al. The impact of obesity and diabetes mellitus on the risk of hepatocellular carcinoma. Ann Oncol. 2009;20(2):353-357.

27. Regimbeau JM, Colombat M, Mognol P, et al. Obesity and diabetes as a risk factor for hepatocellular carcinoma. Liver Transpl. 2004; 10(2 Suppl 1):S69-S73.

28. Takamatsu S, Noguchi N, Kudoh A, et al. Influence of risk factors for metabolic syndrome and non-alcoholic fatty liver disease on the progression and prognosis of hepatocellular carcinoma. Hepatogastroenterology. 2008;55(82-83):609-614.

29. Ascha MS, Hanouneh IA, Lopez R, Tamimi TA, Feldstein AF, Zein NN. The incidence and risk factors of hepatocellular carcinoma in patients with nonalcoholic steatohepatitis. Hepatology. 2010;51(6):1972-1978.

30. Chen CJ, Wang LY, Lu SN, et al. Elevated aflatoxin exposure and increased risk of hepatocellular carcinoma. Hepatology. 1996;24(1): $38-42$.

31. Sanyal AJ, Yoon SK, Lencioni R. The etiology of hepatocellular carcinoma and consequences for treatment. Oncologist. 2010;15 Suppl 4 $14-22$.

32. Villanueva A, Newell P, Hoshida Y. Inherited hepatocellular carcinoma. Best Pract Res Clin Gastroenterol. 2010;24(5):725-734.

33. Fattovich G, Stroffolini T, Zagni I, Donato F. Hepatocellular carcinoma in cirrhosis: incidence and risk factors. Gastroenterology. 2004; 127(5 Suppl 1):S35-S50.

34. Dragani TA. Risk of HCC: genetic heterogeneity and complex genetics. J Hepatol. 2010;52(2):252-257. 
35. Fracanzani AL, Conte D, Fraquelli M, et al. Increased cancer risk in a cohort of 230 patients with hereditary hemochromatosis in comparison to matched control patients with non-iron-related chronic liver disease. Hepatology. 2001;33(3):647-651.

36. Caballeria L, Pares A, Castells A, Gines A, Bru C, Rodes J. Hepatocellular carcinoma in primary biliary cirrhosis: similar incidence to that in hepatitis C virus-related cirrhosis. Am J Gastroenterol. 2001;96(4):1160-1163.

37. Bruix J, Sherman M. Management of hepatocellular carcinoma: an update. Hepatology. 2011;53(3):1020-1022.

38. National Comprehensive Cancer Network. National Comprehensive Cancer Network Clinical Practice Guidelines in Oncology: Hepatobiliary Cancers. Version 2. 2012. Available from: http://www. nccn.org/professionals/physician_gls/pdf/hepatobiliary.pdf. Accessed January 27, 2012.

39. Zhang BH, Yang BH, Tang ZY. Randomized controlled trial of screening for hepatocellular carcinoma. J Cancer Res Clin Oncol. 2004;130(7):417-422.

40. Wong LL, Limm WM, Severino R, Wong LM. Improved survival with screening for hepatocellular carcinoma. Liver Transpl. 2000;6(3):320-325.

41. Sherman M. Serological surveillance for hepatocellular carcinoma: time to quit. $J$ Hepatol. 2010;52(4):614-615.

42. Bolondi L, Sofia S, Siringo S, et al. Surveillance programme of cirrhotic patients for early diagnosis and treatment of hepatocellular carcinoma: a cost effectiveness analysis. Gut. 2001;48(2):251-259.

43. Chen TH, Chen CJ, Yen MF, et al. Ultrasound screening and risk factors for death from hepatocellular carcinoma in a high risk group in Taiwan. Int J Cancer. 2002;98(2):257-261.

44. Yao FY. Should surveillance for hepatocellular carcinoma be increased in patients with cirrhosis and small liver nodules? Nat Clin Pract Gastroenterol Hepatol. 2006;3(10):544-545.

45. Breedis C, Young G. The blood supply of neoplasms in the liver. Am J Pathol. 1954;30(5):969-977.

46. Miller G, Schwartz LH, D'Angelica M. The use of imaging in the diagnosis and staging of hepatobiliary malignancies. Surg Oncol Clin N Am. 2007;16(2):343-368.

47. Forner A, Vilana R, Ayuso C, et al. Diagnosis of hepatic nodules $20 \mathrm{~mm}$ or smaller in cirrhosis: prospective validation of the noninvasive diagnostic criteria for hepatocellular carcinoma. Hepatology. 2008;47(1):97-104.

48. Yeh JJ, Uemura M. Hepatocellular carcinoma. $N$ Engl J Med. 2012;366(1):92; author reply 92-93.

49. Wee A. Fine needle aspiration biopsy of hepatocellular carcinoma and hepatocellular nodular lesions: role, controversies and approach to diagnosis. Cytopathology. 2011;22(5):287-305.

50. Pawlik TM, Gleisner AL, Anders RA, Assumpcao L, Maley W, Choti MA. Preoperative assessment of hepatocellular carcinoma tumor grade using needle biopsy: implications for transplant eligibility. Ann Surg. 2007;245(3):435-442.

51. Silva MA, Hegab B, Hyde C, Guo B, Buckels JA, Mirza DF. Needle track seeding following biopsy of liver lesions in the diagnosis of hepatocellular cancer: a systematic review and meta-analysis. Gut. 2008;57(11):1592-1596.

52. Torzilli G, Minagawa M, Takayama T, et al. Accurate preoperative evaluation of liver mass lesions without fine-needle biopsy. Hepatology. 1999;30(4):889-893.

53. Levy I, Greig PD, Gallinger S, Langer B, Sherman M. Resection of hepatocellular carcinoma without preoperative tumor biopsy. Ann Surg. 2001;234(2):206-209.

54. Lok AS, Lai CL. alpha-Fetoprotein monitoring in Chinese patients with chronic hepatitis B virus infection: role in the early detection of hepatocellular carcinoma. Hepatology. 1989;9(1):110-115.

55. Lok AS, Sterling RK, Everhart JE, et al. Des-gamma-carboxy prothrombin and alpha-fetoprotein as biomarkers for the early detection of hepatocellular carcinoma. Gastroenterology. 2010;138(2): 493-502.
56. Marrero JA, Feng Z, Wang Y, et al. Alpha-fetoprotein, des-gamma carboxyprothrombin, and lectin-bound alpha-fetoprotein in early hepatocellular carcinoma. Gastroenterology. 2009;137(1):110-118.

57. Sangiovanni A, Manini MA, Iavarone M, et al. The diagnostic and economic impact of contrast imaging techniques in the diagnosis of small hepatocellular carcinoma in cirrhosis. Gut. 2010;59(5):638-644.

58. Bruix J, Castells A, Bosch J, et al. Surgical resection of hepatocellular carcinoma in cirrhotic patients: prognostic value of preoperative portal pressure. Gastroenterology. 1996;111(4):1018-1022.

59. Llovet JM, Fuster J, Bruix J. Intention-to-treat analysis of surgical treatment for early hepatocellular carcinoma: resection versus transplantation. Hepatology. 1999;30(6):1434-1440.

60. Kubota K, Makuuchi M, Kusaka K, et al. Measurement of liver volume and hepatic functional reserve as a guide to decisionmaking in resectional surgery for hepatic tumors. Hepatology. 1997;26(5):1176-1181.

61. Shoup M, Gonen M, D’Angelica M, et al. Volumetric analysis predicts hepatic dysfunction in patients undergoing major liver resection. $J$ Gastrointest Surg. 2003;7(3):325-330.

62. Abdalla EK, Hicks ME, Vauthey JN. Portal vein embolization: rationale, technique and future prospects. Br J Surg. 2001;88(2):165-175.

63. Farges O, Belghiti J, Kianmanesh R, et al. Portal vein embolization before right hepatectomy: prospective clinical trial. Ann Surg. 2003;237(2):208-217.

64. Vauthey JN, Dixon E, Abdalla EK, et al. Pretreatment assessment of hepatocellular carcinoma: expert consensus statement. HPB (Oxford). 2010;12(5):289-299.

65. Pawlik TM, Poon RT, Abdalla EK, et al. Critical appraisal of the clinical and pathologic predictors of survival after resection of large hepatocellular carcinoma. Arch Surg. 2005;140(5):450-457; discussion $457-458$.

66. Chok KS, Ng KK, Poon RT, Lo CM, Fan ST. Impact of postoperative complications on long-term outcome of curative resection for hepatocellular carcinoma. Br J Surg. 2009;96(1):81-87.

67. Yang LY, Fang F, Ou DP, Wu W, Zeng ZJ, Wu F. Solitary large hepatocellular carcinoma: a specific subtype of hepatocellular carcinoma with good outcome after hepatic resection. Ann Surg. 2009;249(1):118-123.

68. Tjandra JJ, Fan ST, Wong J. Peri-operative mortality in hepatic resection. Aust N Z J Surg. 1991;61(3):201-206.

69. Arii S, Yamaoka Y, Futagawa S, et al. Results of surgical and nonsurgical treatment for small-sized hepatocellular carcinomas: a retrospective and nationwide survey in Japan. The Liver Cancer Study Group of Japan. Hepatology. 2000;32(6):1224-1229.

70. Shi M, Guo RP, Lin XJ, et al. Partial hepatectomy with wide versus narrow resection margin for solitary hepatocellular carcinoma: a prospective randomized trial. Ann Surg. 2007;245(1):36-43.

71. Kianmanesh R, Regimbeau JM, Belghiti J. Selective approach to major hepatic resection for hepatocellular carcinoma in chronic liver disease. Surg Oncol Clin N Am. 2003;12(1):51-63.

72. Sasaki A, Iwashita Y, Shibata K, Ohta M, Kitano S, Mori M. Preoperative transcatheter arterial chemoembolization reduces longterm survival rate after hepatic resection for resectable hepatocellular carcinoma. Eur J Surg Oncol. 2006;32(7):773-779.

73. Ono T, Yamanoi A, Nazmy El Assal O, Kohno H, Nagasue N. Adjuvant chemotherapy after resection of hepatocellular carcinoma causes deterioration of long-term prognosis in cirrhotic patients: metaanalysis of three randomized controlled trials. Cancer. 2001;91(12):2378-2385.

74. Printz C. Clinical trials of note. Sorafenib as adjuvant treatment in the prevention of disease recurrence in patients with hepatocellular carcinoma (HCC) (STORM). Cancer. 2009;115(20):4646.

75. Mazzaferro V, Regalia E, Doci R, et al. Liver transplantation for the treatment of small hepatocellular carcinomas in patients with cirrhosis. N Engl J Med. 1996;334(11):693-699.

76. Martin AP, Bartels M, Hauss J, Fangmann J. Overview of the MELD score and the UNOS adult liver allocation system. Transplant Proc. 2007;39(10):3169-3174. 
77. Jonas S, Bechstein WO, Steinmuller T, et al. Vascular invasion and histopathologic grading determine outcome after liver transplantation for hepatocellular carcinoma in cirrhosis. Hepatology. 2001;33(5):1080-1086.

78. Figueras J, Ibanez L, Ramos E, et al. Selection criteria for liver transplantation in early-stage hepatocellular carcinoma with cirrhosis: results of a multicenter study. Liver Transpl. 2001;7(10):877-883.

79. Duffy JP, Vardanian A, Benjamin E, et al. Liver transplantation criteria for hepatocellular carcinoma should be expanded: a 22-year experience with 467 patients at UCLA. Ann Surg. 2007;246(3):502-509; discussion 509-511.

80. Yao FY, Ferrell L, Bass NM, Bacchetti P, Ascher NL, Roberts JP. Liver transplantation for hepatocellular carcinoma: comparison of the proposed UCSF criteria with the Milan criteria and the Pittsburgh modified TNM criteria. Liver Transpl. 2002;8(9):765-774.

81. Lee SG, Hwang S, Moon DB, et al. Expanded indication criteria of living donor liver transplantation for hepatocellular carcinoma at one large-volume center. Liver Transpl. 2008;14(7):935-945.

82. Yao FY, Ferrell L, Bass NM, et al. Liver transplantation for hepatocellular carcinoma: expansion of the tumor size limits does not adversely impact survival. Hepatology. 2001;33(6):1394-1403.

83. Hsu HC, Wu TT, Wu MZ, Sheu JC, Lee CS, Chen DS. Tumor invasiveness and prognosis in resected hepatocellular carcinoma. Clinical and pathogenetic implications. Cancer. 1988;61(10):2095-2099.

84. Llovet JM, Bruix J, Gores GJ. Surgical resection versus transplantation for early hepatocellular carcinoma: clues for the best strategy. Hepatology. 2000;31(4):1019-1021.

85. Poon RT. Optimal initial treatment for early hepatocellular carcinoma in patients with preserved liver function: transplantation or resection? Ann Surg Oncol. 2007;14(2):541-547.

86. Lencioni R, Llovet JM. Modified RECIST (mRECIST) assessment for hepatocellular carcinoma. Semin Liver Dis. 2010;30(1):52-60.

87. Riaz A, Ryu RK, Kulik LM, et al. Alpha-fetoprotein response after locoregional therapy for hepatocellular carcinoma: oncologic marker of radiologic response, progression, and survival. J Clin Oncol. 2009;27(34):5734-5742.

88. Livraghi T, Bolondi L, Lazzaroni S, et al. Percutaneous ethanol injection in the treatment of hepatocellular carcinoma in cirrhosis. A study on 207 patients. Cancer. 1992;69(4):925-929.

89. Kasugai H, Osaki Y, Oka H, Kudo M, Seki T. Severe complications of radiofrequency ablation therapy for hepatocellular carcinoma: an analysis of 3,891 ablations in 2,614 patients. Oncology (Williston Park). 2007;72 Suppl 1:72-75.

90. Ebara M, Okabe S, Kita K, et al. Percutaneous ethanol injection for small hepatocellular carcinoma: therapeutic efficacy based on 20-year observation. J Hepatol. 2005;43(3):458-464.

91. Brunello F, Veltri A, Carucci P, et al. Radiofrequency ablation versus ethanol injection for early hepatocellular carcinoma: A randomized controlled trial. Scand J Gastroenterol. 2008;43(6):727-735.

92. Lencioni RA, Allgaier HP, Cioni D, et al. Small hepatocellular carcinoma in cirrhosis: randomized comparison of radio-frequency thermal ablation versus percutaneous ethanol injection. Radiology. 2003;228(1):235-240.

93. Shiina S, Teratani T, Obi S, et al. A randomized controlled trial of radiofrequency ablation with ethanol injection for small hepatocellular carcinoma. Gastroenterology. 2005;129(1):122-130.

94. Cho YK, Kim JK, Kim MY, Rhim H, Han JK. Systematic review of randomized trials for hepatocellular carcinoma treated with percutaneous ablation therapies. Hepatology. 2009;49(2):453-459.

95. Orlando A, Leandro G, Olivo M, Andriulli A, Cottone M. Radiofrequency thermal ablation vs percutaneous ethanol injection for small hepatocellular carcinoma in cirrhosis: meta-analysis of randomized controlled trials. Am J Gastroenterol. 2009;104(2):514-524.

96. Bouza C, Lopez-Cuadrado T, Alcazar R, Saz-Parkinson Z, Amate JM. Meta-analysis of percutaneous radiofrequency ablation versus ethanol injection in hepatocellular carcinoma. BMC Gastroenterol. 2009;9:31.
97. Livraghi T, Goldberg SN, Lazzaroni S, Meloni F, Solbiati L, Gazelle GS. Small hepatocellular carcinoma: treatment with radiofrequency ablation versus ethanol injection. Radiology. 1999;210(3): 655-661.

98. Mazzaferro V, Battiston C, Perrone S, et al. Radiofrequency ablation of small hepatocellular carcinoma in cirrhotic patients awaiting liver transplantation: a prospective study. Ann Surg. 2004;240(5):900-909.

99. Llovet JM, Vilana R, Bru C, et al. Increased risk of tumor seeding after percutaneous radiofrequency ablation for single hepatocellular carcinoma. Hepatology. 2001;33(5):1124-1129.

100. Lu DS, Yu NC, Raman SS, et al. Radiofrequency ablation of hepatocellular carcinoma: treatment success as defined by histologic examination of the explanted liver. Radiology. 2005;234(3):954-960.

101. Sala M, Llovet JM, Vilana R, et al. Initial response to percutaneous ablation predicts survival in patients with hepatocellular carcinoma. Hepatology. 2004;40(6):1352-1360.

102. Livraghi T, Giorgio A, Marin G, et al. Hepatocellular carcinoma and cirrhosis in 746 patients: long-term results of percutaneous ethanol injection. Radiology. 1995;197(1):101-108.

103. Lin SM, Lin CJ, Lin CC, Hsu CW, Chen YC. Randomised controlled trial comparing percutaneous radiofrequency thermal ablation, percutaneous ethanol injection, and percutaneous acetic acid injection to treat hepatocellular carcinoma of $3 \mathrm{~cm}$ or less. Gut. 2005;54(8): 1151-1156.

104. Livraghi T, Meloni F, Di Stasi M, et al. Sustained complete response and complications rates after radiofrequency ablation of very early hepatocellular carcinoma in cirrhosis: is resection still the treatment of choice? Hepatology. 2008;47(1):82-89.

105. Chen MS, Li JQ, Zheng Y, et al. A prospective randomized trial comparing percutaneous local ablative therapy and partial hepatectomy for small hepatocellular carcinoma. Ann Surg. 2006;243(3):321-328.

106. Lü MD, Kuang M, Liang LJ, et al. Surgical resection versus percutaneous thermal ablation for early-stage hepatocellular carcinoma: a randomized clinical trial [Chinese]. Zhonghua Yi Xue Za Zhi. 2006;86(12):801-805.

107. Lewandowski RJ, Geschwind JF, Liapi E, Salem R. Transcatheter intraarterial therapies: rationale and overview. Radiology. 2011;259(3): 641-657.

108. Biolato M, Marrone G, Racco S, et al. Transarterial chemoembolization (TACE) for unresectable HCC: a new life begins? Eur Rev Med Pharmacol Sci. 2010;14(4):356-362.

109. Varela M, Real MI, Burrel M, et al. Chemoembolization of hepatocellular carcinoma with drug eluting beads: efficacy and doxorubicin pharmacokinetics. J Hepatol. 2007;46(3):474-481.

110. Raoul JL, Guyader D, Bretagne JF, et al. Randomized controlled trial for hepatocellular carcinoma with portal vein thrombosis: intra-arterial iodine-131-iodized oil versus medical support. $\mathrm{J} \mathrm{Nucl}$ Med. 1994;35(11):1782-1787.

111. Kulik LM, Carr BI, Mulcahy MF, et al. Safety and efficacy of $90 \mathrm{Y}$ radiotherapy for hepatocellular carcinoma with and without portal vein thrombosis. Hepatology. 2008;47(1):71-81.

112. Llovet JM, Real MI, Montana X, et al. Arterial embolisation or chemoembolisation versus symptomatic treatment in patients with unresectable hepatocellular carcinoma: a randomised controlled trial. Lancet. 2002;359(9319):1734-1739.

113. Lo CM, Ngan H, Tso WK, et al. Randomized controlled trial of transarterial lipiodol chemoembolization for unresectable hepatocellular carcinoma. Hepatology. 2002;35(5):1164-1171.

114. Dhanasekaran R, Kooby DA, Staley CA, Kauh JS, Khanna V, Kim HS. Comparison of conventional transarterial chemoembolization (TACE) and chemoembolization with doxorubicin drug eluting beads (DEB) for unresectable hepatocelluar carcinoma (HCC). J Surg Oncol. 2010;101(6):476-480.

115. Lammer J, Malagari K, Vogl T, et al. Prospective randomized study of doxorubicin-eluting-bead embolization in the treatment of hepatocellular carcinoma: results of the PRECISION V study. Cardiovasc Intervent Radiol. 2010;33(1):41-52. 
116. Malagari K, Pomoni M, Kelekis A, et al. Prospective randomized comparison of chemoembolization with doxorubicin-eluting beads and bland embolization with BeadBlock for hepatocellular carcinoma. Cardiovasc Intervent Radiol. 2010;33(3):541-551.

117. Salem R, Lewandowski RJ, Kulik L, et al. Radioembolization results in longer time-to-progression and reduced toxicity compared with chemoembolization in patients with hepatocellular carcinoma. Gastroenterology. 2011;140(2):497-507.

118. Molinari M, Kachura JR, Dixon E, et al. Transarterial chemoembolisation for advanced hepatocellular carcinoma: results from a North American cancer centre. Clin Oncol (R Coll Radiol). 2006;18(9): 684-692.

119. El-Serag HB, Marrero JA, Rudolph L, Reddy KR. Diagnosis and treatment of hepatocellular carcinoma. Gastroenterology. 2008;134(6): 1752-1763.

120. Maluccio MA, Covey AM, Porat LB, et al. Transcatheter arterial embolization with only particles for the treatment of unresectable hepatocellular carcinoma. J Vasc Interv Radiol. 2008;19(6): 862-869

121. Gish RG, Porta C, Lazar L, et al. Phase III randomized controlled trial comparing the survival of patients with unresectable hepatocellular carcinoma treated with nolatrexed or doxorubicin. J Clin Oncol. 2007;25(21):3069-3075.

122. Parikh PM, Fuloria J, Babu G, et al. A phase II study of gemcitabine and cisplatin in patients with advanced hepatocellular carcinoma. Trop Gastroenterol. 2005;26(3):115-118.

123. Llovet JM, Sala M, Castells L, et al. Randomized controlled trial of interferon treatment for advanced hepatocellular carcinoma. Hepatology. 2000;31(1):54-58.

124. Yeo W, Mok TS, Zee B, et al. A randomized phase III study of doxorubicin versus cisplatin/interferon alpha-2b/doxorubicin/ fluorouracil (PIAF) combination chemotherapy for unresectable hepatocellular carcinoma. J Natl Cancer Inst. 2005;97(20): 1532-1538.

125. Barbare JC, Bouche O, Bonnetain F, et al. Randomized controlled trial of tamoxifen in advanced hepatocellular carcinoma. J Clin Oncol. 2005;23(19):4338-4346.

126. Melia WM, Johnson PJ, Williams R. Controlled clinical trial of doxorubicin and tamoxifen versus doxorubicin alone in hepatocellular carcinoma. Cancer Treat Rep. 1987;71(12):1213-1216.

127. Randomized trial of leuprorelin and flutamide in male patients with hepatocellular carcinoma treated with tamoxifen. Hepatology. 2004;40(6):1361-1369.

128. Becker G, Allgaier HP, Olschewski M, Zahringer A, Blum HE. Long-acting octreotide versus placebo for treatment of advanced HCC: a randomized controlled double-blind study. Hepatology. 2007;45(1):9-15.

129. Barbare JC, Bouche O, Bonnetain F, et al. Treatment of advanced hepatocellular carcinoma with long-acting octreotide: a phase III multicentre, randomised, double blind placebo-controlled study. Eur J Cancer. 2009;45(10):1788-1797.

130. Llovet JM, Ricci S, Mazzaferro V, et al. Sorafenib in advanced hepatocellular carcinoma. $N$ Engl J Med. 2008;359(4):378-390.

131. Cheng AL, Kang YK, Chen Z, et al. Efficacy and safety of sorafenib in patients in the Asia-Pacific region with advanced hepatocellular carcinoma: a phase III randomised, double-blind, placebo-controlled trial. Lancet Oncol. 2009;10(1):25-34.

132. Liu L, Cao Y, Chen C, et al. Sorafenib blocks the RAF/MEK/ERK pathway, inhibits tumor angiogenesis, and induces tumor cell apoptosis in hepatocellular carcinoma model PLC/PRF/5. Cancer Res. 2006;66(24):11851-11858.

133. Huynh H. Molecularly targeted therapy in hepatocellular carcinoma. Biochem Pharmacol. 2010;80(5):550-560.

134. Raoul JL, Santoro A, Beaugrand A, et al. Efficacy and safety of sorafenib in patients with advanced hepatocellular carcinoma according to ECOG performance status: a subanalysis from the SHARP trial. J Clin Oncol. May 26, 2008;Suppl 20:Abstr 4587.
135. Park YN. Update on precursor and early lesions of hepatocellular carcinomas. Arch Pathol Lab Med. 2011;135(6):704-715.

136. Borzio M, Fargion S, Borzio F, et al. Impact of large regenerative, low grade and high grade dysplastic nodules in hepatocellular carcinoma development. J Hepatol. 2003;39(2):208-214.

137. Villanueva A, Minguez B, Forner A, Reig M, Llovet JM. Hepatocellular carcinoma: novel molecular approaches for diagnosis, prognosis, and therapy. Annu Rev Med. 2010;61:317-328.

138. Paradis V, Bieche I, Dargere D, et al. Molecular profiling of hepatocellular carcinomas (HCC) using a large-scale real-time RT-PCR approach: determination of a molecular diagnostic index. Am J Pathol. 2003;163(2):733-741.

139. Llovet JM, Chen Y, Wurmbach E, et al. A molecular signature to discriminate dysplastic nodules from early hepatocellular carcinoma in HCV cirrhosis. Gastroenterology. 2006;131(6):1758-1767.

140. Nam SW, Park JY, Ramasamy A, et al. Molecular changes from dysplastic nodule to hepatocellular carcinoma through gene expression profiling. Hepatology. 2005;42(4):809-818.

141. Wurmbach E, Chen YB, Khitrov G, et al. Genome-wide molecular profiles of $\mathrm{HCV}$-induced dysplasia and hepatocellular carcinoma. Hepatology. 2007;45(4):938-947.

142. Di Tommaso L, Franchi G, Park YN, et al. Diagnostic value of HSP70, glypican 3, and glutamine synthetase in hepatocellular nodules in cirrhosis. Hepatology. 2007;45(3):725-734

143. Di Tommaso L, Destro A, Seok JY, et al. The application of markers (HSP70 GPC3 and GS) in liver biopsies is useful for detection of hepatocellular carcinoma. J Hepatol. 2009;50(4):746-754.

144. Liu H, Li P, Zhai Y, et al. Diagnostic value of glypican-3 in serum and liver for primary hepatocellular carcinoma. World J Gastroenterol. 2010;16(35):4410-4415.

145. Bertino G, Ardiri AM, Calvagno GS, Bertino N, Boemi PM. Prognostic and diagnostic value of des-gamma-carboxy prothrombin in liver cancer. Drug News Perspect. 2010;23(8):498-508.

146. Toyoda H, Kumada T, Tada T, et al. Clinical utility of highly sensitive Lens culinaris agglutinin-reactive alpha-fetoprotein in hepatocellular carcinoma patients with alpha-fetoprotein $<20 \mathrm{ng} / \mathrm{mL}$. Cancer Sci. 2011;102(5):1025-1031.

147. DurazoFA, BlattLM, Corey WG, et al. Des-gamma-carboxyprothrombin, alpha-fetoprotein and AFP-L3 in patients with chronic hepatitis, cirrhosis and hepatocellular carcinoma. J Gastroenterol Hepatol. 2008;23(10):1541-1548.

148. Vandecaveye V, De Keyzer F, Verslype C, et al. Diffusion-weighted MRI provides additional value to conventional dynamic contrastenhanced MRI for detection of hepatocellular carcinoma. Eur Radiol. 2009;19(10):2456-2466.

149. Tan CH, Low SC, Thng CH. APASL and AASLD Consensus Guidelines on Imaging Diagnosis of Hepatocellular Carcinoma: a review. Int J Hepatol. 2011;2011:1-11.

150. Marin D, Di Martino M, Guerrisi A, et al. Hepatocellular carcinoma in patients with cirrhosis: qualitative comparison of gadobenate dimeglumine-enhanced MR imaging and multiphasic 64-section CT. Radiology. 2009;251(1):85-95.

151. Di Martino M, Marin D, Guerrisi A, et al. Intraindividual comparison of gadoxetate disodium-enhanced MR imaging and 64-section multidetector CT in the detection of hepatocellular carcinoma in patients with cirrhosis. Radiology. 2010;256(3):806-816.

152. Sun HY, Lee JM, Shin CI, et al. Gadoxetic acid-enhanced magnetic resonance imaging for differentiating small hepatocellular carcinomas ( $<$ or $=2 \mathrm{~cm}$ in diameter) from arterial enhancing pseudolesions: special emphasis on hepatobiliary phase imaging. Invest Radiol. 2010;45(2):96-103.

153. Ahn JH, Yu JS, Hwang SH, Chung JJ, Kim JH, Kim KW. Nontumorous arterioportal shunts in the liver: CT and MRI findings considering mechanisms and fate. Eur Radiol. 2010;20(2):385-394.

154. Khan MA, Combs CS, Brunt EM, et al. Positron emission tomography scanning in the evaluation of hepatocellular carcinoma. J Hepatol. 2000;32(5):792-797. 
155. Kim YK, Lee KW, Cho SY, et al. Usefulness 18F-FDG positron emission tomography/computed tomography for detecting recurrence of hepatocellular carcinoma in posttransplant patients. Liver Transpl. 2010;16(6):767-772.

156. Ho CL, Chen S, Yeung DW, Cheng TK. Dual-tracer PET/CT imaging in evaluation of metastatic hepatocellular carcinoma. $\mathrm{J} \mathrm{Nucl} \mathrm{Med}$. 2007;48(6):902-909.

157. Eisenhauer EA, Therasse P, Bogaerts J, et al. New response evaluation criteria in solid tumours: revised RECIST guideline (version 1.1). Eur J Cancer. 2009;45(2):228-247.

158. World Health Organization. WHO Handbook for Reporting Results of Cancer Treatment. Geneva: WHO; 1979.

159. Forner A, Ayuso C, Varela M, et al. Evaluation of tumor response after locoregional therapies in hepatocellular carcinoma: are response evaluation criteria in solid tumors reliable? Cancer. 2009;115(3): 616-623.

160. Mannelli L, Kim S, Hajdu CH, Babb JS, Clark TW, Taouli B. Assessment of tumor necrosis of hepatocellular carcinoma after chemoembolization: diffusion-weighted and contrast-enhanced MRI with histopathologic correlation of the explanted liver. AJR Am J Roentgenol. 2009;193(4):1044-1052.
161. Chen G, Ma DQ, He W, Zhang BF, Zhao LQ. Computed tomography perfusion in evaluating the therapeutic effect of transarterial chemoembolization for hepatocellular carcinoma. World $J$ Gastroenterol. 2008;14(37):5738-5743.

162. Maksimovic O, Schraml C, Hartmann JT, et al. Evaluation of response in malignant tumors treated with the multitargeted tyrosine kinase inhibitor sorafenib: a multitechnique imaging assessment. AJR Am J Roentgenol. 2010;194(1):5-14.

163. Villanueva A, Llovet JM. Targeted therapies for hepatocellular carcinoma. Gastroenterology. 2011;140(5):1410-1426.

164. Hoshida Y, Nijman SM, Kobayashi M, et al. Integrative transcriptome analysis reveals common molecular subclasses of human hepatocellular carcinoma. Cancer Res. 2009;69(18):7385-7392.

165. Ji J, Shi J, Budhu A, et al. MicroRNA expression, survival, and response to interferon in liver cancer. $N$ Engl $J$ Med. 2009;361(15): 1437-1447.

166. Roessler S, Jia HL, Budhu A, et al. A unique metastasis gene signature enables prediction of tumor relapse in early-stage hepatocellular carcinoma patients. Cancer Res. 2010;70(24):10202-10212.

167. Kew MC. Prevention of hepatocellular carcinoma. Ann Hepatol. 2010;9(2):120-132.
Biologics: Targets \& Therapy

\section{Publish your work in this journal}

Biologics: Targets \& Therapy is an international, peer-reviewed journal focusing on the patho-physiological rationale for and clinical application of Biologic agents in the management of autoimmune diseases, cancers or other pathologies where a molecular target can be identified. This journal is indexed on PubMed Central, CAS, EMBase, Scopus

Submit your manuscript here: http://www.dovepress.com/biologics-targets--therapy-journal

\section{Dovepress}

and the Elsevier Bibliographic databases. The manuscript management system is completely online and includes a very quick and fair peerreview system, which is all easy to use. Visit http://www.dovepress. com/testimonials.php to read real quotes from published authors. 